\title{
Randomised trial of dopamine compared with hydrocortisone for the treatment of hypotensive very low birthweight infants
}

\author{
David Bourchier, Philip J Weston
}

\begin{abstract}
Aim-To compare the efficacy of hydrocortisone with dopamine for the treatment of hypotensive, very low birthweight (VLBW) infants.

Methods-Forty infants were randomly allocated to receive either hydrocortisone $(n=21)$ or dopamine $(n=19)$.

Results-All 19 infants randomised to dopamine responded; 17 of 21 (81\%) did so in the hydrocortisone group. Three of the four non-responders in the hydrocortisone group had clinically significant left to right ductal shunting. The incidence of bronchopulmonary dysplasia, retinopathy of prematurity, intraventricular haemorrhage, necrotising enterocolitis, symptomatic patent ductus arteriosus, hyperglycaemia, sepsis (bacterial or fungal) or survival did not differ between groups. The adrenocorticotrophic hormone (ACTH) stimulated plasma cortisol activity, either before or after treatment, did not differ between the two groups of infants. Although a significant difference in efficacy between dopamine and hydrocortisone was not noted $(P=0.108)$, there were four treatment failures in the hydrocortisone group, compared with none in the dopamine group.

Conclusion-Both hydrocortisone and dopamine are effective treatments for hypotension in very low birthweight infants.
\end{abstract}

(Arch Dis Child 1997;76:F174-F178)

Keywords: hydrocortisone; dopamine; hypotension; very low birthweight; plasma cortisol

Hypotension in very low birthweight (VLBW) infants is associated with both intraventricular haemorrhage ${ }^{1-3}$ and poor neurodevelopmental outcome. ${ }^{4}$ The pathophysiological basis for the hypotension is poorly understood, although factors such as reduced plasma cortisol ${ }^{5}$ and ductal patency ${ }^{6}$ may be important.

In 1987 Wood et al ${ }^{7}$ showed that there was a

Newborn Intensive Care,

Waikato Hospital, Private Bag 3200, Hamilton,

New Zealand

D Bourchier

P J Weston

Correspondence to: Dr Bourchier.

Accepted 2 January 1997 subsequently noted an increase in systemic Candida sp infections in a case-control series. ${ }^{12}$

Other studies have shown that volume expansion is less effective than the early use of dopamine $e^{13}$ in conditions where there is a poor correlation between blood pressure and blood volume. ${ }^{14-16}$

Given the importance of hypotension as a problem among VLBW infants and the increasing use of corticosteroids in its management, we undertook a randomised trial to test the hypothesis that hydrocortisone is as effective as dopamine in treating hypotensive VLBW infants.

\section{Method}

During the period July 1993-June 1995, 40 hypotensive VLBW infants requiring inotropic support were enrolled in the study. Entry criteria were: (a) birthweight $<1500 \mathrm{~g}$; (b) age $<7$ days; (c) absence of major congenital abnormality; (d) absence of shock (such as early onset sepsis or massive feto-maternal transfusion) requiring immediate inotropic or blood product support; (e) absence of a clinically significant patent ductus arteriosus (PDA) (LA:Ao $>1.5$ or diameter $>1.5 \mathrm{~mm}$ ) after the age of 3 days; (f) informed parental consent.

Hypotension $^{2}$ was defined as a MAP of less than $25 \mathrm{~mm} \mathrm{Hg}$ (birthweight 500-749 g), 30 mm Hg (birthweight 750-999 g), 35 mm Hg (birthweight 1000-1499 g) on two occasions 30 minutes apart. Infants were randomly allocated to receive either dopamine or hydrocortisone if they remained hypotensive following a single dose of colloid $(10 \mathrm{ml} / \mathrm{kg}$ of $4 \%$ albumin) given intravenously over 20 minutes. If an infant responded to the initial dose of colloid but became hypotensive in the ensuing two hours they were also randomised as above. After randomisation (sealed envelopes containing random number table allocation) an ACTH stimulated cortisol test was performed using Synacthen $35 \mathrm{mcg} / \mathrm{kg}$ intravenously. ${ }^{17}$ One $\mathrm{ml}$ of blood was collected before and 30 minutes after Synacthen administration and stored at $4^{\circ} \mathrm{C}$ until assayed. Twenty four hours after stopping either hydrocortisone or dopamine treatment the ACTH stimulated cortisol test was repeated. Plasma cortisol was measured using a fluorometric enzyme immunoassay (Baxter Diagnostics) with interassay and intra-assay coefficients of variation of $6.8 \%$ and $5 \%$, respectively, and a sensitivity of 8.5 $\mathrm{nmol} / 1$. Cross reaction for naturally occurring adrenal steroids was less than $3 \%$ except for 11-deoxycortisol at $6.8 \%$. 
Table 1 Patient characteristics (mean(SD))

\begin{tabular}{llll}
\hline & $\begin{array}{l}\text { Dopamine } \\
(n=19)\end{array}$ & $\begin{array}{l}\text { Hydrocortisone } \\
(n=21)\end{array}$ & P value \\
\hline Birthweight (g) & $1043(184)$ & $923(188)$ & $=0.048$ \\
Gestation (weeks) & $27.5(1.6)$ & $26.6(2.1)$ & $>0.05$ \\
M:F & $9: 10$ & $9: 12$ & $>0.05$ \\
Age at onset of treatment (hours) & $15.1(10.1)$ & $11.4(13.0)$ & $>0.05$ \\
Respiratory distress syndrome (n=) & 17 & 18 & $>0.05$ \\
Surfactant (n=) & 18 & 21 & $>0.05$ \\
Maternal steroids (n=) & 4 & 9 & $>0.05$ \\
Colloid/blood given in 12 hours before & & $17.4(9.1)$ & $>0.05$ \\
$\quad$ treatment (ml/kg) & $15.1(10.5)$ & $41(21)$ & $>0.05$ \\
$\begin{array}{l}\text { Inspired FIO }(\%) \\
\text { Median MAP deficit at entry (mm Hg) }\end{array}$ & 3 & 5 & $>0.05$ \\
\hline
\end{tabular}

Dopamine was infused at an initial dose of 5 $\mathrm{mcg} / \mathrm{kg} / \mathrm{minute}$, increasing stepwise to a maximum dose of $20 \mathrm{mcg} / \mathrm{kg} / \mathrm{minute}$ if necessary. If hypotension persisted a noradrenaline infusion (0.05-0.5 $\mathrm{mcg} / \mathrm{kg} / \mathrm{minute)}$ was added. Once normotension had been maintained for 24 hours, the inotropes were reduced over a 24-48 hour period, as tolerated. Infants in the hydrocortisone group received the initial two doses of hydrocortisone $(2.5 \mathrm{mg} / \mathrm{kg})$ intravenously 4 hours apart. Subsequent doses were given 6 hourly for the remainder of the treatment period. The initial dose $(2.5 \mathrm{mg} / \mathrm{kg})$ was continued for 48 hours, followed by $1.25 \mathrm{mg} / \mathrm{kg}$ for 48 hours, then $0.625 \mathrm{mg} / \mathrm{kg}$ for a further 48 hours before stopping treatment. If, following a reduction in dose, hypotension recurred, the dose was increased to that previously administered for a another 24 hours before attempting further reduction. Persisting hypotension after the first dose of hydrocortisone was managed by a further dose of colloid. If hypotension continued or developed after the second dose of hydrocortisone (before dose reduction), this was judged a treatment failure and the infant was prescribed dopamine. The dose of hydrocortisone was that used in our unit in the treatment of refractory hypoglycaemia and which had been observed to raise blood pressure. The aim of treatment was to maintain the MAP above the hypotensive limits described before. This was the target MAP.

Heart rate, MAP, inspired oxygen concentration and amount of supplementary fluid (colloid, blood products) were recorded at 0,2 , $4,8,12,18,24,30$, and 36 hours from start of treatment, then 12 hourly until study completion at 168 hours. Serum sodium, potassium, and creatinine were measured 12 hourly, together with a blood and urinalysis for glucose. Fluid intake and urine output were calculated daily in $\mathrm{ml} / \mathrm{kg} /$ hour. The infants were nursed in a thermoneutral environment and received 60 to $180 \mathrm{ml} / \mathrm{kg} /$ day of parenteral nutrition, depending on postnatal age and serum sodium. An echocardiogram, including colour and Doppler studies, was performed on day 3 (or earlier if hypotension persisted despite initiation of treatment) using an Advanced Technology Laboratories Ultramark 9 scanner with $5 \mathrm{mHz}$ transducer.

The primary outcome measure was persisting hypotension despite treatment. Secondary outcome measures were the correlation between plasma cortisol concentrations and response to treatment and the effect of treatment on these values. The following clinical outcomes were also recorded: survival; intraventricular haemorrhage (graded 1 to 4 , as per Papille $\left.{ }^{18}\right)$; bronchopulmonary dysplasia $\left(\mathrm{O}_{2}\right.$ requirement at 36 weeks corrected gestation); retinopathy of prematurity; sepsis (positive blood cultures with signs of systemic illness) from the onset of treatment until 14 days (bacterial) or 42 days (fungal) after it had been stopped.

Pre-study power analysis showed that to detect a $20 \%$ failure rate in one group compared with the other $(\alpha-0.05, \beta=0.2), 19$ infants would be needed in each group. Parametric data were analysed using Analysis of Variance (ANOVA) with repeated measures for blood pressure results, and $t$ tests for other single comparisons. The $\chi^{2}$ and Fisher's exact tests were used to analyse differences in proportions, Mann-Whitney U tests for nonparametric comparisons, and Pearson's correlation coefficients were used to determine correlations between cortisol values and inotropic support. In all cases an $\alpha$-value of 0.05 was used to determine significance.

The study was approved by the Waikato Hospital Ethics Committee.

\section{Results}

During the two years of study, 145 infants with a birthweight $<1500 \mathrm{~g}$ were admitted to the Waikato Hospital Newborn Unit. Fifty six $(38.6 \%)$ were hypotensive in the first week of life and potentially eligible for the study. Three were shocked, requiring immediate blood product and inotropic support; consent was declined in one and there were 13 enrolment failures (the physician omitted to approach parents). The remaining 39 were enrolled in the study, plus one infant from Christchurch Hospital (total number 40).

Nineteen infants were randomised to the dopamine group and 21 to the hydrocortisone group. Patient characteristics and details at onset of treatment were similar for both groups (table 1), except that the dopamine group were of larger birthweight than the other group. The median deficit between the MAP at study entry and the target MAP was $3 \mathrm{~mm} \mathrm{Hg}$ (range 1-12) for the dopamine group, and $5 \mathrm{~mm} \mathrm{Hg}$ (range 0-12) for the hydrocortisone group.

In both groups blood pressure improved. The averaged MAPs for each group rapidly reached and remained above the target level throughout the study period (fig 1). ANOVA with repeated measures confirmed a difference between the two groups $(P<0.05)$, with the hydrocortisone group having a consistently higher MAP from 48 hours onwards. This difference most probably reflects the variation in weaning schedules. The hydrocortisone group was weaned slowly by fixed decrements over 144 hours; the dopamine group was weaned as rapidly as the MAP would allow. This slower weaning of the hydrocortisone group meant that three of the infants became hypertensive (MAPs of 55, 55, $45 \mathrm{~mm} \mathrm{Hg}$ at birthweights of 668, 805, and $679 \mathrm{~g}$, respectively) and their treatment was curtailed at 48,72 , and 120 hours. 


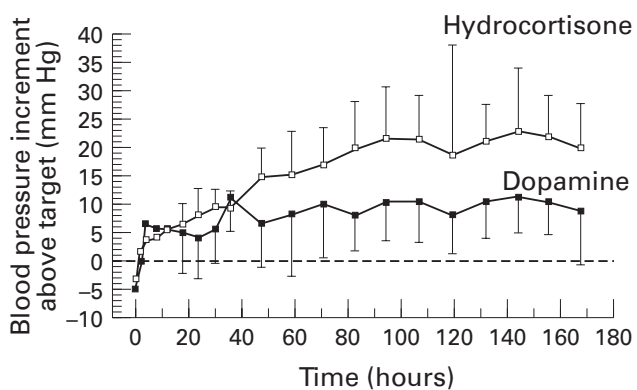

Figure 1 Blood pressure changes over time. Average $M A P s$ at each recording time are shown for both groups as increments above target MAPs (as target MAP varied with birthweight). Data from the four infants who failed in the hydrocortisone group are excluded from the time they stopped receiving hydrocortisone. Vertical bars indicate standard deviations (SD).

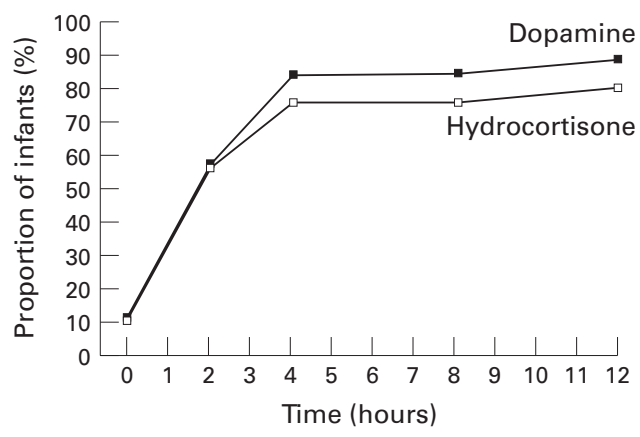

Figure 2 Proportion of infants with MAP above target value in first 12 hours after treatment.

There were four treatment failures in the hydrocortisone group (4-15 hours after treatment initiation), whereas all of the dopamine group achieved target MAPs $(P=0.108)$. The four infants who failed in the hydrocortisone group were successfully treated with dopamine. Three of these infants had clinically significant ductal shunting (left to right), and as the incidence of PDA was no different in the two groups, hypotension associated with PDA was evidently more successfully averted with dopamine than with hydrocortisone.

Over the first 12 hours, the rate of successful treatment was the same for both groups (fig 2). There was no difference in this time period in either the number of infants receiving additional (colloid or blood product) fluid support or the amount received. Seventeen infants in the dopamine group received 15.1 (SD 10.5) $\mathrm{ml} / \mathrm{kg}$ in the 12 hours before treatment and 66.5 (39.2) $\mathrm{ml} / \mathrm{kg}$ during treatment $(\mathrm{n}=18)$. By comparison, in the hydrocortisone group 19 infants received $17.4 \quad(9.1) \quad \mathrm{ml} / \mathrm{kg}$ before treatment and $57.3(48.4) \mathrm{ml} / \mathrm{kg}$ during treatment $(n=19)$.

The maximum dose of dopamine ranged from $5-20 \mathrm{mcg} / \mathrm{kg} /$ minute (median = 10) with a mean duration of treatment of 90.6 hours (range 17-265 hours). No infant required a noradrenaline infusion.

Before treatment there was no difference between the groups in cortisol concentrations either before or after ACTH, and the incremental change on stimulation was also similar (table 2). No significant intergroup difference was noted at 0 or 30 minutes after treatment.
The age at post-treatment sampling was different because the dopamine group tended to reach the end of treatment before the hydrocortisone group.

The pre-treatment cortisol concentrations were analysed in the dopamine group to determine any correlation between them and maximum inotropic requirement. There was no relation between the pre-treatment basal cortisol values and the subsequent maximum dopamine dose $(r=0.13, P>0.05)$, nor between pre-treatment cortisol increment and maximum dopamine dose $(\mathrm{r}=0.38, \mathrm{P}>0.05)$.

There was no difference in outcome for all variables measured (table 3 ). The hydrocortisone group did not show an increased rate of sepsis. There were four infants in this group who developed sepsis, all with coagulase negative staphylococci. In the dopamine group there were six cases, of which three had coagulase negative staphylococci, two group B streptococci, and one Enterococcus faecalis. No episode of fungal sepsis was noted in either group in the study period. An insulin infusion for hyperglycaemia was required in five of the dopamine group and in seven of the hydrocortisone group (not significantly different).

\section{Discussion}

Hypotension in VLBW infants is a recognised risk factor in the pathogenesis of intraventricular haemorrhage $\mathrm{e}^{1-3}$ and is known independently to affect neurodevelopmental outcome at 24 months. ${ }^{4}$ Although the aetiology of the hypotension in these infants is poorly understood, evidence suggests a pivotal role for corticosteroids in mediating the effects of endogenous catecholamines. This phenomenon could be explained by either a direct effect of the corticosteroids on the myocardium or vessel wall or, indirectly, via an increase in adrenergic receptor numbers. Several clinical studies provide further evidence for the importance of corticosteroids. Firstly, infants born to mothers who received antenatal corticosteroids are less likely to become hypotensive than those born to mothers who did not. ${ }^{19}{ }^{20}$ Secondly, Scott $e t a \bar{p}$ reported that hypotensive infants requiring inotropic support had lower plasma cortisol values than those who remained normotensive. Furthermore, two retrospective clinical studies $^{10}{ }^{11}$ have reported a significant improvement in blood pressure in infants with refractory hypotension following corticosteroid treatment. In one of these studies ${ }^{11}$ pretreatment plasma cortisol values were measured and found to be low.

We found ACTH stimulated plasma cortisol concentrations similar to those reported by Thomas, ${ }^{17}$ with basal values significantly higher than those reported by Scott, ${ }^{5}$ Helbock, ${ }^{11}$ and Saedi. $^{21}$ The variation in reported plasma cortisol reflects the different methods of assay (radioimmunoassay, or fluorescence immunoassay) and the differences in the study populations where gestation, postnatal age, severity of illness and time of sampling all differed. The pre-treatment basal plasma cortisols did not predict either the likelihood of successful treatment in the hydrocortisone group or the dose 
Table 2 ACTH atimulated plasma cortisols before and after treatment (mean(SD))

\begin{tabular}{|c|c|c|c|c|}
\hline & \multicolumn{2}{|l|}{ Before } & \multicolumn{2}{|l|}{ After } \\
\hline & $\begin{array}{l}\text { Hydrocortisone } \\
(n=21)\end{array}$ & $\begin{array}{l}\text { Dopamine } \\
(n=19)\end{array}$ & $\begin{array}{l}\text { Hydrocortisone } \\
(n=14)\end{array}$ & $\begin{array}{l}\text { Dopamine } \\
(n=17)\end{array}$ \\
\hline Age (hours) & $11.0(12.8)$ & $14.6(10.3)$ & $181.4(53.3)^{\star}$ & $128.4(63.7)^{\star}$ \\
\hline \multicolumn{5}{|l|}{$\begin{array}{l}\text { Plasma cortisol } \\
\text { (nmol/1): }\end{array}$} \\
\hline 0 mins & 414.8 (394.9) & $411.9(262.1)$ & $619.3(542.5)$ & $541.9(351.4)$ \\
\hline 30 mins & $580.5(455.4)$ & $657.8(448.4)$ & $975.0(621.7)$ & $1077.0(536.1)$ \\
\hline Increment & $166.8(142.4)$ & $215.7(314.3)$ & 355.7 (178.9) & $536.3(284.7)$ \\
\hline
\end{tabular}

$\star=\mathrm{P}<0.05$, Mann-Whitney $\mathrm{U}$ test.

Table 3 Outcome

\begin{tabular}{lllll}
\hline & \multicolumn{2}{l}{ Dopamine } & & \multicolumn{2}{l}{ Hydrocortisone } & \\
\cline { 2 - 2 } & No $(\%)$ & & No(\%) & P value \\
\hline Treatment success & $19(100)$ & & $17(81)$ & $=0.108$ \\
Survival & $18(95)$ & & $19(90)$ & $>0.05$ \\
Bronchopulmonary dysplasia & $2 / 18(11)$ & & $5 / 19(26)$ & $>0.05$ \\
Retinopathy of prematurity (stage 2-4) & $3 / 18(17)$ & & $4 / 19(21)$ & $>0.05$ \\
Intraventricular haemorrhage (grades 2-4) & $3 / 19(16)$ & & $5 / 21(24)$ & $>0.05$ \\
Necrotising enterocolitis & $1 / 19(5)$ & & $4 / 21(19)$ & $>0.05$ \\
Symptomatic patent ductus ateriosus & $9 / 19(47)$ & & $8 / 21(38)$ & $>0.05$ \\
Insulin requirement & $5 / 19(26)$ & $7 / 21(33)$ & $>0.05$ \\
Sepsis & $6 / 19(32)$ & $4 / 21(19)$ & $>0.05$
\end{tabular}

of dopamine required (maximum dose or duration of treatment). Thus our data do not support the premise that cortisol deficiency is a significant factor in the pathogenesis of hypotension in these infants.

Fewer infants were successfully treated with hydrocortisone $(81 \%)$ compared with dopamine $(100 \%)$, although the magnitude and rapidity of response in the initial 12 hours was similar in both groups. The subsequent greater response in MAP between 48 and 168 hours in the hydrocortisone group most probably reflects the different weaning regimens in the two groups. Of the four infants who remained hypotensive on hydrocortisone, three had a patent ductus arteriosus PDA $(>3 \mathrm{~mm})$ with significant left to right shunt. Dopamine successfully treated all the hydrocortisone failures, although the three with ductal patency also received indomethacin (successfully closing the ducts). The poorer response to hydrocortisone in the presence of a large PDA is unexplained.

The mechanism by which corticosteroids improve blood pressure is equally poorly understood, with evidence coming from both in vivo $^{78}$ and in vitro ${ }^{22}$ animal studies and indirectly from patients with corticosteroid excess who become hypertensive. Proposed mechanisms of action can be divided into two broad groups: those which increase synthesis of a specific protein or those which enhance vascular sensitivity to catecholamines. ${ }^{24}$ Given the rapid onset of action of the hydrocortisone in this study, the latter mechanism seems to have been the more important, at least initially. Kalsner ${ }^{22}$ postulated that the enhanced vascular sensitivity to catecholamines was due to inhibition of catechol-O-methyltransferase metabolism of catecholamines, while Bassett et $a^{23}$ demonstrated that inhibition of noradrenaline uptake at neuronal and extraneuronal sites increased myocardial sensitivity to noradrenaline following exposure to glucocorticoid or ACTH. Tangalakis et $a l,{ }^{8}$ however, were unable to confirm an increase in vascular sensitivity to noradrenaline in fetal sheep during a cortisol infusion, despite a significant increase in blood pressure. Actions mediated by alterations in protein synthesis include an increase in human polymorph $\beta$-adrenergic receptor number by up to $40 \%$ in a four hour period after administration of cortisone acetate. ${ }^{25}$ Mano et $a l^{26}$ noted a $70 \%$ increase in rat pulmonary $\beta$-adrenergic receptor density after nine days of hydrocortisone, with similar phenomena reported in rabbits ${ }^{27}$ but not sheep. ${ }^{9}$ The increase in $\beta$-adrenergic receptors in the peripheral blood is mirrored by similar increases in the myocardium. ${ }^{28}$ In addition to increasing $\beta$-adrenergic receptor numbers, corticosteroids enhance adenylate cyclase activity following agonist stimulation ${ }^{29}$ via enhanced gene transcription. ${ }^{30}$ Otten et $a l^{11}$ have shown that two of the key enzymes in catecholamine synthesis - namely, tyrosine hydroxylase and dopamine-B-hydroxylase - are induced by corticosteroids in the presence of other factors. Similarly, angiotensin 2 (type 1) receptor gene expression in fetal lamb cardiac tissue is increased following cortisol infusion. ${ }^{32}$

Potential disadvantages of corticosteroids include hyperglycaemia, adrenal suppression, and increased infection risk. Surprisingly, we noted no evidence of blood glucose disturbance despite using a dose of hydrocortisone which we have found to be effective in the treatment of refractory hypoglycaemia. Although the plasma cortisol response to ACTH after treatment was less in the hydrocortisone group, there was no difference between the basal plasma cortisols. This does not represent a significant degree of adrenal suppression. Unlike Botas et al, ${ }^{12}$ we found no increase in bacterial or fungal sepsis. Other randomised trials $^{33}{ }^{34}$ of postnatal corticosteroid treatment in VLBW infants have also failed to show an increased incidence of such infections.

Current management of the hypotensive VLBW infant includes colloid, inotropes (especially dopamine) and corticosteroids in refractory cases. Given that blood pressure is poorly correlated with blood volume, ${ }^{14-16}$ and that fluid overload may be important in the aetiology of ductal patency and bronchopulmonary dysplasia, colloid should be used judiciously. Despite the effectiveness of dopamine, ${ }^{35}$ there are concerns regarding its potential to increase both pulmonary ${ }^{36}$ and renal ${ }^{37}$ vascular resistances, and to diminish cardiac output. ${ }^{38}$ These concerns and reported efficacy of corticosteroids in refractory hypotension led us to evaluate hydrocortisone as an alternative agent. Hydrocortisone was as effective as dopamine, which is the most commonly used inotrope in such infants. The small sample size and magnitude of effect sought may have hidden less clinically significant, but potentially important, differences. Hydrocortisone was easily administrated as a slow, parenteral bolus, thus obviating the need for a dedicated intravenous line and eliminating the risk of an inadvertent inotrope bolus. Dopamine, however, had the advantage of being more easily titrated according to response. 
In summary, both dopamine and hydrocortisone are effective treatments for hypotension in very low birthweight infants. Future studies evaluating different corticosteroids and tapering regimens seem justified.

We thank Drs P Heron, T Watson, and B Darlow for their clinical contributions.

1 Bada HS, Korones SB, Perry EH, Arheart KL, Ray JD, Pourcyrous M, et al. Mean arterial blood pressure changes in premature infants and those at risk for intraventricular haemorrhage $\mathcal{F}$ Pediatr 1990;117:607-14

2 Watkins AMC, West CR, Cooke RWI. Blood pressure and cerebral haemorrhage and ischemia in very low birthweight infants. Early Hum Dev 1989;19:103-10.

3 Miall-Allen VM, De Vries IS, Whitelaw AGL. Mean arterial blood pressure and neonatal cerebral lesions. Arch arterial blood pressure and

4 Goldstein RF, Thompson RJ, Oehler JM, Brazy JE. Influence of acidosis, hypoxemia and hypotension on neurodevelopmental outcome in very low birthweight infants. Pediatrics 1995;95:238-43.

5 Scott S, Watterberg KL. Effect of gestational age, postnatal age and illness on plasma cortisol concentrations in premature infants. Pediatr Res 1995;37:112-16.

6 Evans N, Iyer P. Changes in blood pressure after treatment of patent ductus arteriosus with indomethacin. Arch Dis Child 1993;68:584-7.

7 Wood CE, Cheung CY, Brace RA. Fetal heart rate, arterial pressure and blood volume resp

8 Tangalakis K, Lumbers ER, Moritz KM, Wintour EM. Effect of cortisol on blood pressure and vascular reactivity in the ovine fetus. Exper Physiol 1992;77:709-17.

9 Stein HM, Oyama K, Martinez A, Chappell BA, Buhl E, Blount $\mathrm{L}$, et al. Effects of corticosteroids in preterm sheep
on adaptation and sympathoadrenal mechanisms at birth. on adaptation and sympathoadren

10 Fauser A, Pohlandt F, Bartmann P, Gortner L. Rapid increase of blood pressure in extremely low birthweight infants after a single dose of dexamethasone. Eur $\mathcal{F}$ Pediatr 1993;152:354-6.

11 Helbock HJ, Insoft RM, Conte FA. Glucocoticoidresponsive hypotension in extremely low birthweight newborns. Pediatrics 1993;92:715-17.

12 Botas C, Kurlat I, Young SM, Sola A. Disseminated candidal infections and intravenous hydrocortisone in preterm infants. Pediatrics 1995;95:883-7.

13 Gill AB, Weindling AM. Randomised controlled trial of plasma protein fraction versus dopamine in hypotensive very low birthweight infants. Arch Dis Child 1993;69:284very

14 Bauer K, Linderkamp D, Versmold HT. Systolic blood pressure and blood volume in preterm infants. Arch Dis Child 1993; 69:521-2.

15 Wright IMR, Goodall SR. Blood pressure and blood volume in preterm infants. Arch Dis Child 1994; 70:F230-2.

16 Barr PA, Bailey PE, Summers J, Cassady G. Relation between arterial blood pressure and blood volume and effect of infused albumin in sick preterm infants. Pediatric 1977;60:282-9.

17 Thomas S, Murphy JF, Dyas J, Ryalls M, Hughes IA Response to ACTH in the newborn. Arch Dis Child 1986;61:57-60.

18 Papille LS, Burstein J, Burstein R, Koffler H. Incidence and evolution of the subependymal intraventricular haemorrhage: a study of infants with weights less than 1500 grams. F Pediatr 1978:92:529-34.
19 Garland JS, Buck R, Leviton A. Effect of maternal glucocorticoid exposure on risk of severe intraventricular haemorrhage in surfactant-treated preterm infants. 7 Pediatr 1995;126:272-9.

20 Moise AA, Wearden ME, Kozinetz CA, Gest AL, Welty SE, Hansen TN. Antenatal steroids are associated with less need for blood pressure support in extremely premature infants. Pediatrics 1995;95:845-50.

21 Saedi SA,Dean H, Dent W, Cronin C. Reference ranges for serum cortisol and 17-hydroxyprogesterone levels in preterm infants. F Pediatr 1995;126:985-7.

22 Kalsner S. Mechanism of hydrocortisone potentiation of responses to epinephrine and norepinephrine in rabbit aorta. Circ Res 1969;24:383-95.

23 Bassett JR, Strand FL, Cairncross KD. Glucocorticoids, adrenocorticotropic hormone and related polypeptides on myocardial sensitivity to noradrenaline. Eur $\mathcal{F}$ Pharmacol 1978;49: 243-9.

24 Orth DN, Kovacs WJ, De Bold CR. The adrenal cortex. In: Wilson JD, Foster DW, eds. Williams Textbook of Endocrinology. 8th edn. Philadelphia: WB Saunders, 1992:518.

25 Davies AO, Lefkowitz RJ. Corticosteroid-induced differential regulation of B-adrenergic receptors in circulating human polymorphonuclear leukocytes and mononuclear leukocytes. F Clin Endocrinol Metab 1980;51:599-605.

26 Mano K, Akbarzadeh A, Townley RG. Effect of hydrocortisone on beta-adrenergic receptors in lung membranes. Life Sci 1979;25:1925-30

27 Cheng JB, Goldfien A, Ballard PL, Roberts JM. Glucocorticoids increase pulmonary B-adrenergic receptors in fetal rabbit. Endocrinology 1980;107:1646-8.

28 Brodde O-E, Michel MC, Gordon EP, Sandoval A, Gilbert EM, Bristow ER. B-adrenoceptor regulation in the human heart: can it be monitored in circulating lymphocytes. Eur Heart $\mathcal{7} 1989 ; 10$ (suppl B): 2-10.

29 Davies AO, Lefkowitz RJ. Regulation of B-adrenergic receptors by steroid hormones. Ann Rev Physiol 1984;46:11930.

30 Collins S, Caron MG, Lefkowitz RJ. Regulation of adrenergic receptor responsiveness through modulation of recep tor gene expression. Ann Rev Physiol 1991;53:497-508.

31 Otten U, Schwab M, Gagnon C, Thoenen H. Selective induction of tyrosine hydroxylase and dopamine B-hydroxylase by nerve growth factor: comparison between adrenal medulla and sympathetic ganglia of adult and newborn rats. Brain Res 1977;133:291-303.

32 Segar JL, Bedell K, Page WV, Mazursky JE, Nuyt A-M, Robillard JE. Effect of cortisol on gene expression of the renin - angiotensin system in fetal sheep. Pediatr Res 1995;37:741-6.

33 Avery GB, Fletcher AB, Kaplan M, Brudno D. Controlled trial of dexamethasone in respirator - dependent infants with bronchopulmonary dysplasia. F Pediatr 1985;75:10611 .

34 Cummings JJ, Eugenio DB, Gross SJ. A controlled trial of dexamethasone in preterm infants at high risk for bronchopulmonary dysplasia. N Engl f Med 1989; 320:1505-10

35 Seri I, Tulassay T, Kiszel J, Machau T, Csomor S. Cardiovascular response to dopamine in hypotensive preterm infants with severe hyaline membrane disease. Eur $\mathcal{F}$ Pediatr 1984;142:3-9.

36 Seri I. Cardiovascular, renal and endocrine actions of dopamine in neonates and children. $f$ Pediatr 1995;126:333-44.

37 Feltes TF, Hansen TN, Martin CG, Leblanc AL, Smith S, Giester ME. The effects of dopamine infusion on regional blood flow in newborn lambs. Pediatr Res 1987;21:131-6.

38 Rozé JC, Tohier C, Maingueneau C, Lefèvre M, Mouzard A. Response to dobutamine and dopamine in the hypotensive very preterm infant. Arch Dis Child 1993;69:59-63. 